\title{
Identifying Possible Gaps and Gray Areas in the Draft Universal Health Care Act Implementing Rules and Regulations: a Thematic Analysis of a Roundtable Event on Local Health Systems
}

\author{
Theo Prudencio Juhani Z. Capeding, MD, MPM,1,2 Ma-Ann M. Zarsuelo, RND, MSc, ${ }^{1,2}$ \\ Michael Antonio F. Mendoza, DDM, MA, ${ }^{1,3}$ Ma. Esmeralda C. Silva, MPAf, MSPPM, PhD ${ }^{1,4}$ \\ and Leonardo R. Estacio Jr., MCD, MPH, PhD ${ }^{1,5}$ \\ ${ }^{1}$ University of the Philippines Manila Health Policy Development Hub \\ ${ }_{2}^{2}$ Institute of Health Policy and Development Studies, National Institutes of Health, University of the Philippines Manila \\ ${ }^{3}$ College of Dentistry, University of the Philippines Manila \\ ${ }^{4}$ College of Public Health, University of the Philippines Manila \\ ${ }^{5}$ College of Arts and Sciences, University of the Philippines Manila
}

\begin{abstract}
Background. The Universal Health Care (UHC) Act is a landmark legislation that seeks to improve provision of comprehensive health services through the integration of local health systems. The Department of Health (DOH) conducted a series of roundtable discussions to gather stakeholders' inputs and concerns to refine the initial draft of the Implementing Rules and Regulations (IRR) of UHC.
\end{abstract}

Methods. On April 4, 2019, the Department of Health led a roundtable discussion on the Local Health Systems sections of the UHC IRR in collaboration with University of the Philippines Manila. A total of 65 stakeholders from different sectors participated in a semi-structured roundtable event. The proceedings were audio recorded and transcribed. A thematic analysis was done using NVivo 12 software to document gaps and gray areas identified by the participants.

Results. Concerns of the participants revolved around the following: role of the private sector in local health systems; the integration of different municipal and other component health systems into a province-wide health system; organizational design of the health systems; pooling and utilization of the Special Health Fund (SHF). Gaps and gray areas were concentrated on the transfer of personnel and other health resources to the province-wide system, the composition of the Provincial Health Board, and the utilization and management of the SHF.

Conclusion. The roundtable event acquired various perspectives from stakeholders that could help the DOH identify priority action points that could be resolved at the agency level. The identified themes from the study analysis could be of value to decision makers to clarify issues, address policy gaps, and to prioritize future research directions.

Key Words: Universal healthcare, health systems, health policy, thematic analysis

\section{INTRODUCTION}

Corresponding author: Theo Prudencio Juhani Z. Capeding, MD, MPM

UP Manila Health Policy Development Hub

National Institutes of Health

University of the Philippines Manila

623 Pedro Gil St., Ermita, Manila 1000, Philippines

Email: tzcapeding@up.edu.ph
In early 2019, the Universal Health Care (UHC) Act was signed into law. This signifies the intent of the State to provide a more comprehensive set of health care services through social health insurance and integrated networks. ${ }^{1}$ Based on the experience of other countries that enacted similar laws that tackle national level policy reforms which focused on extending access to health services, the process 
Policy Analysis of UHC Act IRR

will be long and complicated, especially for low to middle income countries. ${ }^{2,3,4}$

The Department of Health (DOH) conducted multiple stakeholder consultations through roundtable discussions and technical working group events for the drafting of the Implementing Rules and Regulations (IRR) of the Universal Health Care Act. These consultations were organized to gather inputs from different stakeholders through the discussion of the initial draft of the IRR. Given the broad yet encompassing sections of the IRR draft and the different sets of stakeholders called per section, the UHC IRR Secretariat divided the draft into related sections for specific and focused discussion. The DOH tapped the UP Manila Health Policy Development Hub as organizing partner in three of these roundtable events. This study focused on one of the themes of these roundtable events: Local Health Systems Integration.

\section{Local Systems Integration as an answer to fragmentation}

Fragmentation issues persist in the current organization of the Philippine health system; characterized by institutional segmentation leading to fragmentation of health financing and service delivery. This fragmentation of the health system is currently manifested in multiple ways, such as the duplication of procurement, services, and infrastructure; uncoordinated financing between agencies and local government units; and the lack of financial accountability. In order to mitigate fragmentation of the devolved aspects of health systems, a shift to an integrated systems model was initiated, wherein close coordination between health providers is strengthened to provide continuous and comprehensive care for healthcare clients. ${ }^{5}$ However, simply implementing the new model that has worked with other countries is not enough and may even worsen inequities between health systems. ${ }^{6,7}$ It is essential to know the current situation and practices in the areas where integration are to be initiated, to contextualize the process of establishing a province-wide health system. ${ }^{8}$

\section{The roundtable policy discussion as venue to gather stakeholder perspectives}

Policy roundtable discussions (RTD) can complement the existing body of knowledge by involving participants with expertise and experience from the different sectors of health. These participants are valuable source of information on issues encountered in the past, on current practices, and on emerging concerns that will be faced by policy makers in the future. ${ }^{9}$ The main objective of this study was to identify perceived gaps raised by the RTD participants. In order to address the challenge of identifying policy gaps from the continuous shifting of discussion between multiple topics, this study used thematic analysis to identify gaps and gray areas in the draft IRR of the UHC Act.

\section{METHODS}

\section{Study design}

The study utilized a descriptive qualitative design, with the RTD transcriptions, and process documentation as inputs in the thematic analysis. An initial inductive thematic analysis was done to identify themes naturally generated by the discussion, and then a second examination of the coded statements focusing on gaps and gray areas was applied.

\section{Participants}

The DOH Health Policy Development and Planning Bureau selected the participants-stakeholders from different sectors, allowing only one representative per organization or agency to ensure balanced representation. A total of 63 representatives participated in the roundtable discussion. Table 1 shows the composition of the group per sector.

Table 1. Roundtable event participants per sector

\begin{tabular}{lc} 
Sector/Group & $\begin{array}{c}\text { Number of } \\
\text { participants }\end{array}$ \\
\hline Department of Health & 19 \\
Academe & 14 \\
Non-government organizations & 2 \\
Professional organizations & 2 \\
Hospitals/Hospital associations & 3 \\
Local health officers & 4 \\
Local government units & 3 \\
Patient organizations & 3 \\
Private sector & 2 \\
Legislative branch (House of Representatives) & 2 \\
Other government agencies & 9 \\
\hline
\end{tabular}

\section{Roundtable discussion}

Judgement sampling was used to identify participants for the roundtable event. Invited organizations and agencies were selected based on their relevance to UHC Law provisions on Local Health Systems. Some agencies were explicitly stated in the Law, while others were selected based on the organization's core functions as they relate to the Law. The list was created by the UHC IRR Core Secretariat and was approved after consulting with different UHC IRR Technical Working Groups. Both the Core Secretariat and Technical Working Groups were organized by the $\mathrm{DOH}$. The participants contributed diverse expertise for the policy issue, with experience from the public and private sector; health management sector from a range of facilities and institutions (e.g., rural health units, provincial health offices, and hospitals); clinical and public health (e.g., professional societies, academe, non-government organizations, and patient organizations); policy makers and implementers from the $\mathrm{DOH}$, other national agencies, and the House of Representatives.

The roundtable discussion was conducted on April 4, 2019 in Hotel Jen, Manila, Philippines. For reference, each participant was provided the copy of Republic Act 11223 
or the UHC Act and the draft IRR which included only the pertinent sections deemed relevant to Local Health Systems' provision in the IRR. Prior to discussing each section, a DOH representative facilitated the sections subject for discussion, after which, comments and insights of the participants were solicited. The discussion was moderated by a designated chair, an Undersecretary of Health from DOH. The proceedings were audio recorded, transcribed, and documented.

\section{Analysis}

Transcriptions of audio recordings were done verbatim using Microsoft Word 2016. The unprocessed transcription was reviewed to identify initial themes and concepts that surfaced during the discussion. Then the Word document was imported to NVivo 12, a qualitative data analysis software. ${ }^{10}$ The language used by the participants, a mix of Filipino and English, were maintained prior to and during the coding process to keep their meaning as intact as possible. Additional attention was given in coding gaps and gray areas identified by the participants. After the initial coding, the organization of codes were then reviewed based on the relationships of the codes and themes. Themes were not patterned to the discussion order set by the DOH. Instead, it was based purely on the analysis of the transcribed data since some statements from participants applied to multiple sections of the IRR. Some statements were selected and quoted to help illustrate key findings. If the statements chosen to be quoted in the paper were initially in Filipino, the statements were translated into English only after the analysis was done. No reliability testing was conducted for the coding in this study.

\section{Limitations of the study}

The authors were third party observers at the roundtable discussion. The selection of participants and the flow of discussion were beyond the control of the observers for this event. While there was a good mix of representation from different stakeholder sectors, time constraints and willingness to fully express concerns might have affected the opportunity and proclivity of some representatives to participate. Future directions for this type of exploratory analysis may consider conducting key informant interviews in order to expound key concerns of stakeholders and bring more depth. The focus of the study was limited to identifying perceived gaps and gray areas. The results of the analysis could be used more objectively by using context analysis or framing analysis of data to control for participant biases and their frames, but these were beyond the scope of the study.

\section{RESULTS}

\section{Theme 1: Role of the private health sector in the local health system}

Participants tackled the role of the private sector in the local health system. The discussion on the topic largely focused on how the private sector will be integrated in the province-wide health system. The private sector's importance was highlighted, for there were areas where majority of care was provided by the private sector, especially for higher level of care. A participant focused on the patient experience, "I think we need to give the private sector a role in the co-creation of the system, because if we excluded them; we are missing out on the opportunity to make it easy for the patient." Further, the same participant added that if patients still had to spend out-of-pocket expenditure for healthcare, after being referred from a public facility to a private one, "...then what is the point." Similarly, another participant underscored the real integration of the private network since ". . . we've always had a duality of health systems in the country. We have a public sector, and an independent private sector doing its own delivery of care. I think we have a wonderful opportunity here with the passage of UHC, to force or facilitate, really integrate these two systems." Majority of the participants agreed that the government shall still be the main driver of the health systems, since they have the accountability to the public. Also, from the perspective of implementers, initially, it would be easier to organize the public sector first.

\section{Moving towards private sector involvement}

The discussion then flowed to the mechanisms of integrating the public and private sectors. Participants seemed to agree that the integration of the private sector can only be resolved in a progressive manner since provinces have different levels of private sector presence in the healthcare system. Two levels of integration were discussed: at the level of service delivery network and at the level of Provincial Health Board. The discussion largely focused on the former, wherein services, and in extension, the resources used in service delivery, were suggested to be all under one network. But this poses legal and administrative concerns brought about by combining private and public funds. Currently, there is no feasible model available to the $\mathrm{DOH}$ that can be adopted wherein public and private providers are truly integrated at the level of sharing resources for health. Neither can the private sector be forced to integrate with the public sector in the delivery of health services. As one participant shared in the roundtable: "in the House Committee [hearings], it was attempted to include mandating the private sector to join. However, we can't compel them because of equal protection of the law."

Mixing private and public funds was recognized to be disadvantageous to the private sector mainly because of two reasons: government auditing and the slow processing of funds. It was made clear by one participant that once government funds are mixed with other sources, the funds will undergo the usual government auditing processes. To bypass this, one idea that was put forth was the contracting out of services to private providers, which was already being done by some local government units. Owing to these perceived limitations brought by auditing and the public 
Policy Analysis of UHC Act IRR

management system, participants suggested that the private sector be part of the Provincial Health Board, so that their sector's concerns can be considered in the planning and coordination of services.

On another note, the feasibility of the private sector as providers of population-based services was brought up, since some of these providers already have a network of healthcare providers from the primary level to tertiary level. This was however, countered by one participant, stressing that simply having connected primary care clinics and tertiary hospitals does not adequately cover population-based services, and that the government should consider tapping groups from the private sector which have "...experience in public health work, public health management, public sector collaboration". Nevertheless, specific set of guidelines for contracting the private sector for population-based services has yet to be formulated.

\section{Theme 2: Integration of the municipal health office under the provincial health office}

For the province-wide health system, the issues that were first raised were about the legality of the integration, one of which revolves around operationalizing the transfer in health personnel and other physical resources. Should there be a transfer of personnel and property ownership to the province? As one participant put it: "There seems to be no expressed provision in the law that there is going to be a transfer, although it appears that that is the intent of the law."

The legitimacy of the UHC Act was further scrutinized in relation to the other two laws that were repeatedly brought up - the Philippine Constitution and the Local Government Code of 1991. A participant quoted Article 10, Section 4 of the Constitution and raised concerns with the "transfer" and commented, "So it describes the principle of subsidiarity and the word used in the constitution is general supervision. Now with the transfer of all these assets, liabilities, personnel and staff like that, there is a semblance of control. That is our problem because how to make a complete integration when we don't have complete control over the component LGU." On the contrary, other participants showed a different perspective: that intent of the UHC Act will not violate the Constitution since it only seeks to consolidate the functions of service provision and health system management at the province level. Another participant supported this, stating that the Constitution even supports the intent of the UHC law.

In seeking to clarify the issue, several participants asked the group to identify municipalities who would lose if health resources would be managed at the province-level. The concern was rooted from two reasons put forth. First, the municipalities would lose control over the health personnel, which are sometimes used for political gains made through medical missions and such. Second, there is "fiscal impact" to the municipalities when real property, land, buildings, and other assets are transferred, decreasing the annual income of the municipalities.
Ensuring the commitment of the municipalities to integration

One of the concerns raised was how to ensure the commitment of municipalities to the integrated provincewide health system. Previous difficulties encountered with organizing Interlocal Health Zones and regarding their sustainability in between change of local leadership were brought up. Participants questioned the operational definition of the provision in the draft IRR, focusing on the phrase "LGUs that will commit". This was deemed problematic by one participant saying, "...it will open the possibility for some mayors not to commit to integration." The same participant emphasized that the wording of the IRR is crucial since this is the legal document to be used when negotiating with local chief executives. One proposed way that would help ensure the commitment to integration is to go through a process of getting expressed approvals from the Sangguniang Bayan (municipal legislative council) through an ordinance, instead of being directed by the IRR.

\section{Personnel concerns with integration: salary standar- dization}

The group recognized that the current reality among health workers across the nation is that their salaries are not standardized. Differences between municipalities exist depending on the LGUs' financial capacity to offer higher salaries. With the shift in organizational and financing scheme at the province level, what then would be the basis for salaries and benefits? One participant suggested that the goal should be for health worker salaries to be standardized regardless of the local government unit since "they have the same functions in one system."

\section{Personnel concerns with integration: administrative and technical supervision}

Another provision which raised clarifications on its wording in the IRR was with administrative and technical supervision: What do the words "supervision" and "oversee" exactly mean as a function of the Provincial Health Board? A participant expounded further: "For example, it is written here, the City Health Office will supervise the primary care provider network. What does 'supervise' mean? Particularly, when we say a network can be public, private, or both. Is there administrative prerogative or is it entirely technical?" Another participant cited Executive Order 292 or the Administrative Code of the Philippines to explain the scope of administrative supervision, "...administrative supervision shall be limited to the authority of the department or its equivalent to generally oversee the operation of sub-agencies to ensure that they are managed efficiently, effectively, and economically without interference with day to day activities..." The participant stressed awareness on the importance of legal matters, and added that they want the $\mathrm{DOH}$ "to avoid unnecessary legal matters in the future, especially if the IRR is challenged." 


\section{Proposed options for facilitating integration}

Recognizing the concerns raised, several ways to move forward were identified. The approach needs to recognize that there was hesitancy and/or unwillingness of municipalities to integrate, and that the government should endeavor to make the integration transition fair and just for them. Three integration options were proposed where basically, it would not incur any cost to the municipalities, at least during the initial years of integration.

The first option (Figure 1) included transferring the plantilla positions to the province-wide health system level while being managed by the Provincial Health Board (PHB). The salaries and benefits of the health personnel will be subsidized by the national government during the transition phase.

The second option (Figure 2) was a similar model used for deploying personnel of the Philippine National Police: "...plantilla positions will be created by DOH to absorb municipal health workers, and then deployed to the provincewide health system under the management and supervision of the PHB."

The third option (Figure 3) proposed was a mix of the two, modeled after the Department of Finance's deployment of municipal treasurers. Municipal health workers will be appointed by the national government, managed and supervised by the PHB, but paid for by the special health fund.

A key difference among the three options was the funding source for personnel salaries. It was proposed that the transfer of responsibility and resources for health from the municipalities to the province-wide system, should not include the municipalities' allocated resources for health. This transfer of responsibility without the transfer of budgeted health funds is expected to "increase fiscal space for municipalities 15-22\%", according to one participant from DOH. Should these options be chosen, a participant reminded the group that the re-organization should be in accordance with the existing laws of RA 6656 (Act to Protect the Security of Tenure of Civil Service Officers and Employees in the Implementation of Government Reorientation).

\section{Theme 3: Organizational design of the provincial health system}

An integral part of the integration of local health systems is the organizational design of the province-wide health system. The discussion was initially focused on the member composition of the Provincial Health Board. The first concern was to whose authority will the appointing board members be and what the criteria of selection would be. For some participants, it was important to ensure that indigenous groups, patient groups, and other civil society groups be included. Also, it was pointed out that there is a need to be more explicit in terms of accountability and transparency in the health board, or as one participant put it, "bow can we make that explicit in terms of their deliverables in the community."

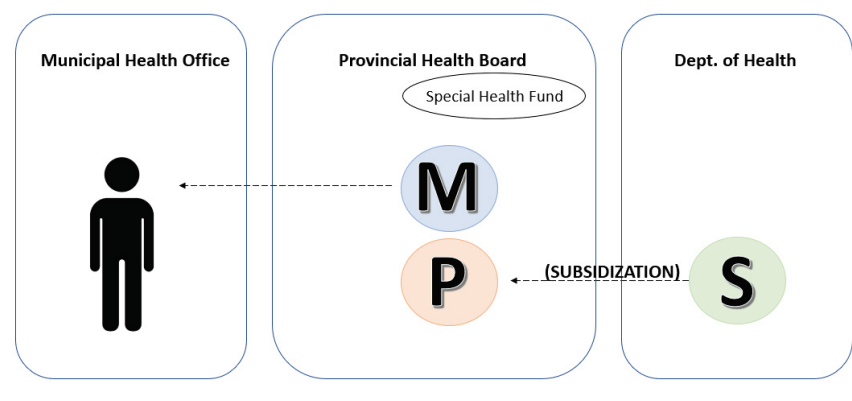

Legend: (M) - management, (P) - plantilla positions, (S) - salaries

Figure 1. Proposed integration Option No. 1: Plantilla position $(P)$ of the health worker is managed $(M)$ by the Provincial Health Board, while salaries (S) for the position is subsidized by the $\mathrm{DOH}$.

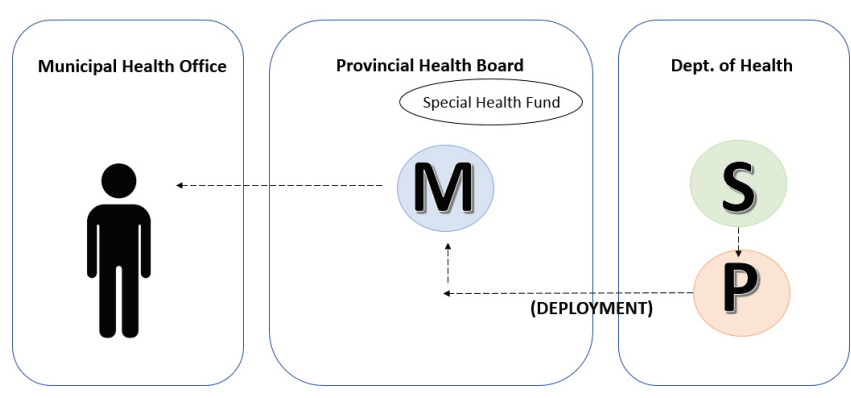

Legend: $(M)$ - management, $(P)$ - plantilla positions, $(S)$ - salaries

Figure 2. Proposed integration Option No. 2: The plantilla positions $(\mathrm{P})$, and the salaries $(\mathrm{S})$ of the health workers are under the $\mathrm{DOH}$, which are in turn deployed by the agency to the PHB.

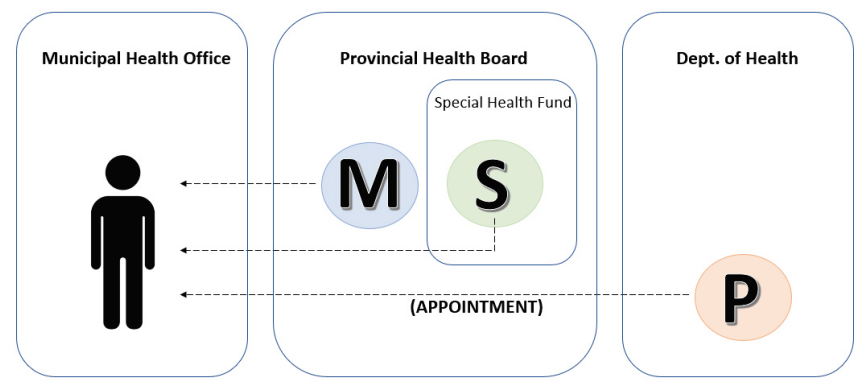

Legend: (M) - management, $(P)$ - plantilla positions, $(S)$ - salaries

Figure 3. Proposed integration option no. 3 Plantilla positions (P) of health workers are under $\mathrm{DOH}$ which in turn are appointed to areas by the agency. Salaries (S) of the health workers are sourced from the special health fund.

The UHC Act prescribes representation from the towns and units under the province-wide system. Hence, it would be logical that for this provision, the larger the province in terms of population and number of component 
Policy Analysis of UHC Act IRR

municipalities, the more members would be in the Provincial Health Board. For some participants, it was difficult to imagine that a PHB where all towns are represented would work. The extent of involvement of the private sector in the health system would also affect the composition of the PHB, "for small provinces, you have a small private sector; the public sector will be very dominant. Compare that to Cebu or Batangas with big private sectors; I think the IRR should be nuanced about this." In line with selection strategies, some participants proposed that the Provincial Health Officers should be given discretion and recommendation on which MHOs and other representative would be deemed necessary to the PHB. On the other hand, some expressed concern in limiting participation via cluster representation, that a "widespread, multi-town" representation must be guaranteed. One participant tried to meld the two opinions together, that if indeed a form of cluster representation is chosen, there should be a documented process of decision making within each cluster before the resolution is forwarded by the cluster representative to the PHB.

\section{Allowing the provincial health offices to restructure}

The participants emphasized that provincial health offices (PHOs) should be allowed to restructure their organization as they see fit in order to "be able to operationalize the spirit of the law." This proposal was brought forth by the concern that using the same organizational structure to run a progressively evolving system might lead to failures in the health system. Hence, it was suggested that the IRR need not be too prescriptive as it might limit the options of PHOs.

\section{Oversight concerns}

As stipulated in the law, the Provincial Health Board will function as the oversight for the whole province-wide health system. Should the PHO be the vice chair to the governor (the de facto overall chair), the $\mathrm{PHO}$ can then preside as the PHB chair in the absence of the governor. This could result to losing "the check function of the PHO" since the PHO is the main implementer in the province-wide health system. In response to this conflict, it was suggested that the $\mathrm{PHO}$ should have a different position within the board. Additional oversight from the DOH Regional Offices, also known as Centers for Health Development (CHD), was also raised by virtue of the CHDs being external to the $\mathrm{PHB}$, as it is important to correct or intervene in non-performing provincial health systems.

\section{Theme 4: Provincial health system}

The next theme covers the operationalization of the integrated province-wide health system. The two main issues discussed in this section were the importance of the health information system, and the capabilities of PHOs and $\mathrm{CHOs}$ to handle health system management.

\section{Objectives and challenges of establishing a health information system}

Participants agreed that a truly integrated health information system must have accessible patient records from the primary care facilities to the apex hospital. The absence of this health information system is a gap that needs to be addressed. In order to be used properly for surveillance and financing, the establishment of a unique patient identifier must be prioritized. According to one participant, since the Philippine National ID System is on the verge of being implemented, this unique patient identifier could be linked to this system for more efficient utility. Interoperability between provinces was also a recommended target goal for the $\mathrm{DOH}$.

One of the perceived challenges on the health data management was the epidemiologic surveillance system in urban areas and big cities. Private health providers are significant contributors in the urban health system; hence, an effective surveillance system would demand data from the private health sector. Therefore, attaining cooperation with these private providers is crucial. If cooperation is not solicited, then the regulatory powers of $\mathrm{DOH}$ over private providers need to be strengthened. It was also noted that difficulties in accessing data was not limited to the private sector, but also extends among and between government agencies wherein access to information from databases, including commissioned researches, is limited. Information and data sharing between agencies need to be improved.

Participants also shared the challenges of establishing an integrated health information system. Using different platforms is very difficult for generating surveillance data according to one participant. In the private sector, the initial challenge was encouraging physicians and other health workers to use electronic medical records. Next would be harmonizing the different information systems available and that are being used. The systems are mostly manufacturerdependent, and even laboratory equipment that automatically generates data have their own system, which makes harmonization hard to achieve. Considerable investment would be needed for a more efficient global platform and sustainability of the system.

\section{Capabilities of provincial health officers and city health officers as health system managers}

Concerns around the competencies and readiness of provincial health officers and other health system implementors were raised. Are they well-equipped with management and technical skills and the knowledge to handle the demands of a province-wide health system? Participants who represented ground level implementers expressed their apprehensions. Hence, the groups recognized that there is a need to ensure that health system managers are qualified based on the demands of the roles. While there are protections provided by the Civil Service Commission, as this is the primary role of the agency; a participant noted 
that "qualification standards of health officers from the smallest units to the largest must be established and administered by the agency concerned" referring to the DOH. Stronger focus on management skills especially on financial housekeeping was recommended. A participant emphasized that "there is a provision found in the chapter on HRH (buman resource for health) where it was conceptualized that there will be management courses for the Provincial Health Team." This could mean that health governance will be strengthened through capacity building.

\section{Theme 5: The Special Health Fund}

Source of pooled funds and the mechanisms of its transfer to the Special Health Fund were the main concerns related to the financing of provincial health systems.

\section{Sources of the Special Health Fund}

The identified main sources of the fund are the $\mathrm{DOH}$ financial grants, Philippine Health Insurance Corporation (PhilHealth) reimbursements or capitation intended for individual-based services, and the regular budget of the province for the maintenance of hospitals, as well as other sources such as foreign-assisted projects grants. This stirred concerns from representatives of the municipalities that led to questions on whether their funds allocated for health will be pooled to the province. There were attempts to address the question during the roundtable, but future dedicated discussions on the issue was deemed appropriate by the group.

\section{Flow of funds to the Special Health Fund}

DOH grants were deemed to be simpler since it would be through budget allocations and can be transferred directly to the Special Health Fund. However, it was emphasized that the grants would be based on the Local Investment Plan for Health. Meanwhile, the case can be more complicated for funds from PhilHealth. First, since it is planned that PhilHealth will pay using a global budget, a reliable costing methodology backed with robust evidence must be used in order to project costs and forward the appropriate amount to the SHF. Second, because PhilHealth reimbursements "are considered under the law as local revenue" the main concern is whether the reimbursements can go straight to the SHF or not. A Constitutional provision was raised where local income accrues exclusively at the local government units. This might mean that the PhilHealth reimbursements have to go through the provincial budget first, after which allocation of funds to the SHF would be done. It was pointed out that since "reimbursements from the PhilHealth are considered national fund, Article $X$, Section $V$ of the Constitution would not apply" to the concerned. Another participant suggested that the system used for the Special Education Fund of the Department of Education be adopted where funds are released straight to the local school boards. Representatives from the $\mathrm{DOH}$ agreed to study the suggestion.

\section{DISCUSSION}

\section{Striking a balance}

An overarching theme in the roundtable discussions was the seeking of balance between clarity and flexibility. Since the formulation of the IRR marks the start of the process of operationalizing the law, it was understandable that the participants took into consideration the clarity of the statements of the draft IRR provisions since this may cause confusion or variations in implementation because of differing interpretations. On the other hand, being too prescriptive and specific might lead to technicalities that will prompt legal issues in the approval process of the IRR. One example is the discussion on the organizational design of provincial health offices where the participants wanted to see a semblance of what is expected from a system, and at the same time give the local health authorities leeway to design their own systems as they see fit. Related to the matter of balance were specific issues on the wording found in the IRR. For example, one issue was related to ensuring commitment of the municipalities to the integrated system. The operational definition of the words "committed to" was a concern of the participants. The participants preferred to avoid the difficulties encountered in the past, during the implementation of Interlocal Health Zones. ${ }^{11}$

\section{Summary of perceived gaps in the draft IRR}

Key perceived gaps emerged from the roundtable discussion. Initial concerns regarding local health systems integration came from the private sector. The main challenge of integrating public and private providers under one network seemed to revolve around concerns on financing. Contracting of health services is seen as the main integrating mechanism by the participants. Contracting resolves issues regarding government auditing that is required by law once public funds are mixed with other sources. There are also considerations to involve the private health sector in population-based services, in which guidelines to ensure coverage on quality of these services have yet to be created. It was generally agreed that public and private integration mechanisms might have to be developed progressively. Available literature on the public-private integration models, however limited, seem to support this view. ${ }^{12}$ The $\mathrm{DOH}$ may need to prepare regulatory guidelines that would allow for innovations at the province-level.

Second, is the integration of the municipal health system to the province-wide system. Based on the responses of the participants, this issue will likely be the main source of problems brought about by legal challenges to the IRR. This unresolved gray area concerns the transfer of personnel and other health resources from municipalities to the province in order to achieve full integration. Upon initial examination, the disagreement presented itself as being drawn between two sides: that integration is in conflict to the Philippine Constitution while for some, integration 
is supported by the Constitution. Pragmatically, the issue can be resolved by consulting constitutional law experts. However, it can be argued that there may be additional benefits in framing the issues differently for stakeholders. To illustrate this point, we examined statements of two participants regarding the legality of local health systems integration. The first participant: "Without complete control over the component $L G U$, it is difficult to make a complete integration" The opposing response from another participant was, "I don't think we are violating the intent of the constitution since we are just consolidating the functions at the province level'. These two statements are telling as they provide a key insight; that the differences between the two views lie in the interpretation and understanding of what integration entails. One side thinks that integration may only be achieved by complete control of component LGUs. There could be many issues that could be clarified regarding the statement. For example, what does complete control mean? What does complete integration mean? This may be caused by a confusion between the different interpretations of the dimensions of integration. ${ }^{13}$ Current literature on integration and integrated care supports this. The lack of common terminology affects discussion of operational understanding and policy formulation. ${ }^{14}$ By clearly delineating the properties of integration, only then can we move toward discussing the features needed to achieve integrated care. ${ }^{14} \mathrm{DOH}$ may consider prioritizing and addressing this issue by partnering with municipal level stakeholders to discuss the remaining issues using operational terms understood by both parties.

Finally, the last set of gaps identified revolved around the expected problems that will be encountered by province-wide health systems post-formation. Participants regarded the challenge of establishing a global health information system as the most difficult. Another concern was the perceived weak capacity of health officers to manage health systems to ensure sustainability and proper financial management of the health systems.

\section{Priority action points for $\mathrm{DOH}$}

The results also identified priority action points which were noted by $\mathrm{DOH}$. These were primarily, features that need to be clearly defined by the agency. The following concerns were agreed to be resolved at the level of the $\mathrm{DOH}$ possibly via guidelines or administrative orders:

1. Guidelines on the standardization and financial management of the salaries and benefits of health personnel if indeed the national budget would cover these items in the initial years of implementing local health system integration.

2. Terms surrounding the appointment of the members of the Provincial Health Boards and the process by which they will be selected.

3. Strategies on making the PHB accountable in terms of health system performance.
4. Definitions for the scope of PHB's supervisory roles, especially for health facilities and human resources from the private sector and private networks.

5. Qualifications for health officers across different levels of the health system.

6. Initiation of inter-agency collaboration among $\mathrm{DOH}$, Department of Budget and Management, and Commission on Audit to resolve issues regarding the Special Health Fund.

\section{CONCLUSION}

The roundtable discussion on the draft UHC IRR for Local Health Systems provided valuable insights from stakeholders on the possible gaps and gray areas, which covered: (1) the role of the private sector in the local health systems, particularly, how they are going to be integrated with public networks; (2) concerns in the integration of the municipal level health system under the province; (3) details surrounding the organizational design of the province-wide health system; (4) management and flow of funds into the Special Health Fund; and (5) other related health system issues that need to be resolved to accomplish a successful integration. The use of an iterative process of thematic analysis, with a specific focus on gaps and gray areas, facilitated the organization of the inputs of the participants.

\section{Statement of Authorship}

All authors participated in data collection and analysis, and approved the final version submitted.

\section{Author Disclosure}

All authors declare no conflicts of interest.

\section{Funding Source} HPSR.

This project was funded by the DOST DOH AHEAD-

\section{REFERENCES}

1. doh.gov.ph. Towards Better Health for All Filipinos: Universal Health Care Law [Internet]. 2019 [cited 2019 Sep 2]. Available from: https://www.doh.gov.ph/press-release-towards-better-health-for-allFilipinos-UHC-signed-into-law.

2. Assefa Y, Gelaw YA, Hill PS, Taye BW, Van Damme W. Community health extension program of Ethiopia, 2003-2018: successes and challenges toward universal coverage for primary healthcare services. Global Health. 2019 Mar; 15(1):24. doi: 10.1186/s12992019-0470-1.

3. Higgins-Steele A, Farewar F, Ahmad F, Qadir A, Edmond K. Towards universal health coverage and sustainable financing in Afghanistan: progress and challenges. J Glob Health. 2018 Dec; 8(2):020308. doi: 10.7189/jogh.08.02038.

4. Umeh CA. Challenges toward achieving universal health coverage in Ghana, Kenya, Nigeria, and Tanzania. Int J Health Plann Manage. 2018 Oct; 33(4):794-805. doi: 10.1002/hpm.2610.

5. World Health Organization. Monitoring the building blocks of health systems: a handbook of indicators and their measurement strategies. Geneva: World Health Organization; 2010. 
6. Ramagem C, Urrutia S, Griffith T, Cruz M, Fabrega R, Holder $\mathrm{R}$, et al. Combating health care fragmentation through integrated health services delivery networks. Int J Integr Care. 2011 Jul-Sep; 11(Suppl):e100.

7. Ferrer L. Integrated health service delivery networks: concepts, policy options and road map for implementation in the Americas. Int J Integr Care. 2013 Jul-Sep; 13:e035.

8. Lega F. Organisational design for health integrated delivery systems: Theory and practice. Health Policy. 2007 May; 81(2-3):258-79. doi: 10.1016/j.healthpol.2006.06.006.

9. Braun V, Clarke V. What can "thematic analysis" offer health and wellbeing researchers? Int J Qual Stud Health Well-being. 2014 Oct; 9:26512 doi: 10.3402/qhw.v9.26152.

10. QSRinternational. NVivo. Version 12. [software]. 2019 [cited 2019 Sep 1] Available from: https://www.qsinternational.com/nvivo/ nvivo-products/nvivo-12-plus.
11. Capuno J, Panganiban M. The ties that do not bind: party affiliations and the delivery of devolved health services in the Philippines. Philipp Political Sci J. 2012 Jun; 33(1):63-80. doi: 10.1080/01154451.2012.684517

12. Billings J, de Weger E. Contracting for integrated health and social care: a critical review of four models. J Integr Care. 2015 Jun; 23(3): 153-75. https://doi.org/10.1108/JICA-03-2015-0015

13. Valentijn PP, Schepman SM, Opheij W, Bruijnzeels MA. Understanding integrated care: a comprehensive conceptual framework based on the integrative functions of primary care. Int J Integr Care. 2013 Mar; 13:e010. doi: 10.5334/ijic.886.

14. Valentijn PP, Boesveld, IC, van der Klauw DM, Ruwaard D, Strujis JN, Molema JJ, et al. Towards a taxonomy for integrated care: a mixed-methods study. Int J Integr Care. 2015 Mar; 15:e03. doi: 10.5334/ijic.1513.

\section{The Acta Medica Philippina is now accepting limited advertising for its front and back cover (colored), as well as for available spaces in some of its pages, as appropriate. For inquiries and submission of proposals, please email us at actamedicaphilippina.upm@up.edu.ph}

